the over-vilified womb and its unfortunate append. ages, is perhaps mainly due to gastric spasm caused by undigested food, occasionally to uterine and ovarian disturbance aciing in a reflex manner.

This hyperkinesis or abnormal motor activity of the muscular tissne of the digestive organs due to vicious diet is, I believe, a much neglected cause of epilepsy. Nocturnal attacks are frequently brought about by an undigested supper; and abuse of the digestive organs, the cause of so many other disorders, is perhaps largely to blame for epilepsy.

I have seen epilepsy cease with the cure of an endometritis, also twice with the repair of a lacerated os. I also saw a case apparently cured by an operation for a congenital epispadias, the operation an adjunct, like the above, to the Niemeyer treatment. The epispadias likely having but little to do with the epilepsy since it preceded it a number of years, the shock of the operation or the impression made on the mind by preparation for the operation so altering the excessive reflex power-evidently the cause of epilepsy-that the seizures ceased. I have also had an inveterate case of the disorder, one but slightly benefited by drug treatment, cured by having her hand so charred in a frying pan that it had to be amputated, after which she had no more attacks of epilepsy up to her death, which occurred four years subsequent from consumption.

I mention these experiences because to the lessons they have taught me in connection with the persistent administration of bromid of potassium in gradually increasing doses and in large quantities of water, the two conditions insisted upon by Niemeyer I may ascribe the success I have had in the manage. of this popularly supposed incurable disease.

I am convinced that the failure of this drug in the hands of so many physicians to cure most cases of epilepsy, and help all, except cases where there is congenital deformity, is due to the lack of persistence in its administration. to not recognizing the necessity of giving it largely diluted in water and according to a regularly graded increase in the quantity prescribed, and also because $I$ am convinced that the failure of the drug in the hands of so many is due, not to its inefficiency, but rather to its improper administration - the importance of its dilution in large quantities of water not being recognized. Even such a one as Brown-Séquard is so careless as to say, in talking of epilepsy: Give 20 or 60 grains of bromid of potassium four times daily, as the case may be, omitting to mention the quantity of menstruum, not apparently know. ing that the salt will bring on the attack, if given in concentrated solution, and that its efficacy in causing cure and amelioration is due to the attenuation in water that facilitates endosmosis and causes a nonirritating assimilation.

The amount given depends entirely on the severity and frequency of the attacks, from 10 to 60 or 90 grains from one to four times daily. The treatment should be continued for at least a year after the cessation of convulsions and in prescribing this drug it should be remembered that a faulty udministration will bring about a recurrence of the attacks.

In addition to the treatment by the drug, resort to the surgeon should be had as occasion requires. Lacerations of the os and other ills of the male or female genitalia should be remedied; constriction of the prepuce in epileptics ought to be corrected; constipation should not be allowed to exist; difficult menstruation cured; suspicious cicatrices should be excised; indigestion should be avoided; the adoption of a suitable dietary is of the greatest importance, allowing but a limited quantity of animal food and but once daily. Epileptics ought to be employed out of doors when possible, and in employment bringing a reward. Distension of the stomach by undigested, fermenting food and impaction of the bowels are a prolific cause of nocturnal attacks. An important point in the treatment of the disease is attention to the mouth, as deformities of the palate, alveolar ab. scesses, necrosis and exfoliation of bone are rather frequent and demand care. All the natural functions should be carefully protected from abuse.

By attending carefully to the above details and others less important perhaps, that my limit precludes me from mentioning and by giving the drug strictly in the way I have indicated, joy, hope and health may be restored to many so-called incurable epileptics, at present abandoned to despair, and many whose existence consists merely of suspense and unconsciousness may be rescued to lives of useful industry, and protected from attacks against which they suppose medicine can oppose no barrier.

$$
\text { Discussion. }
$$

Dr. H. A. West of Galveston, Texas Just before I left Texas I saw a case of about the severest petit mal in a child which ever came under my observation, and I wish to refer to some unusual reflexes in that case. The child had a very long prepuce which I desired to amputate, but the parents would not allow it. In addition it had a persistent and long con. tinued hemorrhage from the bowel. Thinking that this mignt have had something to do with the epilepsy, I directed the use of a solution of subsulphate of iron in the rectum, and also gave bromid of sodium and sulphate of codein. The father told me that the hemorrhage subsided and the number of epileptic attacks was reduced one-fourth or one third. It is evident the reflex disturbances had to do with the epilepsy in that case.

\section{A CASE OF RENAL TUBERCULOSIS.}

Presented to the Section on Practice of Medicine, at the Forty eighth Annual Meeting of the Americau Medical As-ociation, held at Philudelphia, Pr., June 1-4, 1s9.

\section{BY J. DUTTON STEELE, M.D.} PHITADELPHIA, PA

The following case occurred in the wards of Dr. Joseph Hearn in the Philadelphia Hospital. I am indebted to him for the clinical history.

L. H., 23 years of age, a native of Ireland, white and married. There is no tubercular family history. She was admitted in October 1896. The patient had measles in childhood. Influenza five years ago which left her with a "weak right side." In January 1896 she was delivered of a six months fetus and since that time has been confined to bed continually. She has become much emaciated and has a profuse diarrhea. Examination of abdomen shows a large mass the size of a baby's head, in the right lum. bar region. This is movable, and the skin is not adherent. The tumor is not painful except on deep pressure. A slightly tympanic note is heard in percussion over this mass. There is marked edema posteriorly in the lumbar region on the right side, extending up along the thoracic wall. The tumor appears to be distinct from the liver. There is no jaundice. There is no pain in the lumbar region. Micturition is frequent and sometimes painful. Urine : albumin $3 / 4$ by volume. There is much pus, no casts and no blood.

She was transferred to the surgical wards for operation, but this was deemed unadvisable. Her temperature then was 101 degrees, but soon fell to normal and remained subnormal until death. Her breathing was so shallow that physical examination was impossible. Now complains of some pain in the tumor. Is having many large green liquid stools. Examination of urine just before death showed albumin, pus, casts, but no blood. She died October 26.

The autopsy was made by the writer at the Philadelphia Hospital twenty hours after death. The peritoneal cavity is normal except that the liver is pushed forward and barely 
reaches to the costal margin. This is caused by a large tumor lying behind the peritoneum in the right lumbar region. The pleural sacs each contain a small amount of clear fluid. There is thickening of the pleura and adhesions at each apex. The upper lobes of both lungs show considerable consolidation at the upper portion. This is apparently due to a pneumonic process with scattered areas of caseous degeneration, especially about the bronchi. Considerable pus flows from these tubes on section and they contain caseous plugs. At the apex of the right lung is a cavity filled with purulent material. The left kidney is swollen and tense. The capsule strips readily, the cortex is swollen and of a green color, and the pyramids are congested. The pelvis and ureter are normal. The right kidney is found to constitute the tumor mentioned above. It is $25 \mathrm{~cm}$. in length, $18 \mathrm{~cm}$. broad and $15 \mathrm{~cm}$. ihick. The organ is surrounded by a considerable amount of fat that appears normal. On section the kidney is found to be extensively degenerated. The capsule is thickened and firmly adherent. The cortex measures $3 \mathrm{~cm}$. in width, is dense and hard and of a chalky white color with numerous spots of extensive cheesy degeneration. The pyramids are represented by cone-shaped masses, with central cores of cheesy material which empty in to the pelvis which is filled with pus and caseous debris. The wall of the cones are dense and white; the walls of the pelvis are extensively infiltrated and its mucous membrane is ulcerated.

Microscopic examination of the right kidney showed hardly a trace of kidney substance. The capsule was greatly thickened and there was an increase of connective tissue in the walls of the masses that represented the pyramids. Around the margin of the degenerated area were collections of round and epitheloidal cells and occasionally giant cells. A number of sections were stained for the tubercle bacillus but without success. However, the diagnosis of tuberculosis was made upon the characteristic picture presented by the collection of cells, associated with the extensive degeneration.

The wall of the ureter is also much thickened. This infiltra tion extends downward along the whole length of the tube and involves the bladder wall around the orifice of the ureter. The epithelium from the pelvis to the bladder is degenerated and replaced by caseous material, but the lumen does not seem to be obstructed. The epithelium of the bladder has apparently entirely escaped the inflammatory process.

The internal genitalia are perfectly normal. The lymphoid tissue throughout the body is apparently entirely normal. Nothing else of interest is found in the body.

Section of the left kidney revealed much fatty degeneration and chronic parenchymatous nephritis.

After a study of numerous cases reported in the literature of the subject, it seems possible to make three divisions of tuberculosis of the kidney.

1. That which occurs as a part of a general eruption of tubercle, either as a manifestation of acute primary miliary tuberculosis, or as the terminal stage of tuberculosis elsewhere in the body. This condition can not be considered to be more uncommon in the kidneys than in the other abdominal viscera.

2 . In the so-called primary renal tuberculosis, the process either manifests itself in the kidney alone or this organ is undoubtedly the primary focus. This form may be either of the miliary or of the chronic caseous varieties.

3. A form in which the priority of the process in the kidney must be doubted, but in which the disease manifests itself more intensely here than elsewhere. It is associated with foci of tuberculosis in other parts of the body, apparently most often in the bronchial glands, bones or lungs. Under this division must be classed most of the cases of urogenital tuberculosis that have furnished so much discussion concerning their pathogenesis. The difficulty of accurately determining the primary seat of the disease, even in those cases formerly classed as primary in the kidney, is much increased by the possibility of there being some obscure focus of the disease in the body that escapes any but the most careful observation at the postmortem examination-a fact whose importance has been unrecognized until the past decade. Tuberculosis may exist, unsuspected, in the various lymphoid tissues, as the bronchial glands or as lately shown by Dieulafoy and Krückmann in the tonsils.

The authorities on the subjects unite in the statement that the process when once started in the kidney is extremely rapid, and it could only be by most rigid clinical study that it could be determined whether, for instance, pulmonary or renal symptoms were the first to occur.

Senator, in Nothnagel's system, who may be considered to represent the most recent ideas on the subject, doubts whether a strictly primary renal tuberculosis ever exists; but would put all cases under the third division that I have made. He is supported in this view by Steinthal.

Age and sex appear to be predisposing factors in the causation of the disease.

All authorities state that the condition is much more common in adult life than in childhood. Carr found but two instances in 120 autopsies upon children; 16 per cent. of Facklam's cases occurred under 20 years. The disease is very rare in infancy.

Males are affected about twice as often as females as shown by the statistics of Ebstein and Roberts. Osler, Rosentein, Senator and Birsch-Hirschfeld also state that the disease is more frequent in the male sex. However in Facklam's series of 106 cases there were 79 females. Hamill's list gives three times as many boys as girls.

The condition almost invariably commences as a one-sided affection, and in about one-half of the cases the other kidney is involved before death. This furnishes an argument for early operation. The disease does not appear to show any tendency to affect one side oftener than the other. The miliary form commences in the cortex, and the chronic in the medulla. The first may lead to extensive caseous degeneration, but the chronic variety is the one that produces the most extensive necrosis. Occasionally the process commences in the pelvis but usually this escapes until the later stages. The diagnosis from examination of the urine is often difficult as with the pelvis intact the discharge of cheesy material and tubercle bacilli may be entirely prevented. The ureter is usually affected. Its walls are thickened and its epithelium degenerates with the formation of ulcers. The mucous membrane of the bladder very often escapes but its wall is thickened and there are often superficial ulcers upon the trigone. The tubercle bacillus may be found in the tissues in the earlier stages, but at the antopsy the process is commonly too far advanced.

When the kidney is alone affected, most authorities consider the process to be one of hematogenous infection. The best explanation for the presence of the bacilli in the blood stream in the purely primary form, if such exist, is that the microbes have entered through the mucous membranes of the intestinal or respiratory tract without lesion, or in other words by cryptogenic infection. But, after study of a number of reported cases, the writer is satisfied that there is often a cheesy lymph gland at the root of the lung or in the mesentery, that is the means of entrance, for the bacillus to the general circulation.

Meyer of Göttingen, in 1892, described several cases in which a kidney showing chronic tuberculosis, by serial sections, he demonstrated local tubercular foci in the urinary tubules that had not extended from above or below, and which could not have come by penetration of the wall of the tubule, as its membrana propria re- 
mained intact. He explained this by the assumption that the bacilli have been secreted from the blood by the vessels of the glomeruli, found their way along the tubule in the urinary stream and lodging on its wall set up their specific inflammation. He calls this form of infection "Secretion Tuberculosis." He quotes, in support of his theory, Reisser and Orth, who have demonstrated the same process in pyemic abscess of the kidney, and have shown that bacteria and even foreign bodies, as drops of fat, can be secreted through the glomeruli. Borrell, in this experimental production of renal tuberculosis by the injection of the bacilli into the aorta, has demonstrated their presence in the walls of the vessels of the glomeruli, unaccompanied by inflammatory change. Thus there is a second way in which the bacillus in the blood may produce renal tuberculosis.

Time is not given for the consideration of urogenital tuberculosis though the review of the subject does not seem complete without some mention of this form, and the discussion which its pathogenesis has occasioned.

In this variety the kidney, ureters, prostate and testicle in the male, and the tubes and ovaries in the female, are oftenest affected, much more rarely the bladder. This form of the disease is, as is natural, much more common in the male, and indeed is very rare in females.

Rayer, as early as 1837 , showed that a healthy bladder may be an intermediate between a tubercular testis or prostate, and a similar condition of the kidney. The experiments of Alberran, in which by ligation of one ureter and injection of tubercle bacilli into it above the point of ligation, he proved that the disease may ascend along this tract, is conclusive, but is significant as being the only instance, in many experiments by different observers, which was successful. The ascending form is favored by Rokitansky, Lancereaux, Klebs, Steinthal, Guyon, Duret, and Virchow. Later writers, while acknowledging the possibility of an ascending form, incline to the greater frequency of the descending. So Ziegler, Birsch-Hirschfeld, Senator, Carmargo, Dickinson, Roberts, Casper, Hamill and Israel are more or less positive in the opinion that while tuberculosis may ascend the ureter, it is oftenest primary in the kidney.

The case reported belongs to the chronic variety of renal tuberculosis. The sequence of events is doubtful, and the case might reasonably be regarded as one of the rare instances of renal tuberculosis secondary to cryptogenic infection through the mucous membrane of the intestinal or respiratory tract. However, the adhesions at both apices, and the cavity on the right side, together with the fact that the lesions of the lung is of the type of an infection by inhalation, suggests that, probably the disease was primary in the lung, and that the older lesion was masked by a sudden extension of the process about it, at a comparatively late period, and shortly before death.

The histologic portion of the above report is from the Pepper Laboratory of Clinical Medicine. REFERENCES.

Carmargo: Rev. méd. de la Suisse Romande, 1892

Steinthal: Virchow's Arch., rol.c.
Meyer: Virchow's Arch., vol. cxli.

Dieulafoy: Centralbl, für innere medicin, 1895

Hamill: International Med. Mag. September, 1896.

Krückmann : Virchow's A reh., vol. exxxvii.

The Woes of India.-The $N . Y$. Sun correspondent writing from Jhansi, India, June 22, concludes thus: The close of the sixtieth year of the Queen's reign will be remembered in India for its long death roll, its woes, and its disasters.

\section{IS MALARIA A WATER-BORNE DISEASE?}

Presented to the Section on Practice of Medicine at the Forty-eighth Aunual Meeting of the American Medical Association held at Philadelphig, June 1-4, 1897.

\section{BY JOHN M. BATTEN, M.D.}

PITTSBURG, PA.

Malaria may, to some extent, be a water-borne disease, but that the malaria plasmodium or poison gains admittance into the system wholly by way of the stomach, we think we have ample evidence to lead us to doubt. The plasmodium malariæ or malarial poison certainly gains admittance in to the system through the respiratory organs as well.

I will give a hasty review of the disease as it came under my observation in 1864 and 1865. The Valley City, to which I was attached, had a roving permission to cruise in the sounds of North Carolina and up the rivers that empty into these sounds. The water of the sounds at times is brackish, as it has connection with the ocean through Ocracoke Inlet. The intensity of the disease and the number of cases that occurred increased in the following localities in the order named: 1 , the region of the Pamlico River, upon which Wash. ington. N. C., is situated, is rather free from malaria, though cases occur there; 2, the region of Chowan River, Blackwater River, Meherrin River, and 3, the regions of Roanoke River and Neuse River. Again, on Roanoke Island there is no vegetation, except in the northern part of it, where there are a few scrub oaks. The island is sandy and barren. Yet, one day on that island, with Dr. Walton of the 103d Pennsylvania Regiment I saw a hundred cases of malaria, but many of these cases may have been transferred from other localities. The water used there for drinking and cooking purposes was boiled water taken from the wells on the island.

The water for drinking and cooking purposes on the Valley City was either boiled or distilled, taken from the boiler, cooled and kept in a covered vessel for that purpose. Now, when the Valley City was for a long time up the Roanoke River or other rivers, the cases increased in number and intensity, according to the locality in which she cruised. When cruising up the Roanoke River for a long time the treatment of the disease in many instances would be of no avail, but afterward, when cruising in the sounds or the Atlantic Ocean the disease would respond to treatment, so that there would not be a single case of malaria on board. Afterward, cruising up any of the aforesaid rivers the number of cases and the intensity would increase according to the locality. In the region of the Roanoke River it was intensely malarious, as forest swamps and fogs prevailed there, and many places in this region were impenetrable to man or even the wild beasts of that locality. Why was there a difference in the type of the disease and also the number attacked while in these different localities? It was not the water we drank nor the food we ate, for the water we drank and used for cooking purposes was boiled or distilled. The boiler received its water by pumping from the river, sounds or ocean. Therefore the malarial poison must have been taken into the system through the respiratory organs.

In the fall of 1865, at Cairo, Ill., following a very hot and dry summer, the months of September and October were exceptionally dry and hot. I reported for duty on the United States monitor Oneota, lying off Cairo on the Ohio River, Oct. 6, 1865. Malarial fever was prevalent everywhere in that vicinity. A 